\title{
Conditions for Establishing the Optimal-Efficient Scheme of the Process of Flushing of Heat Supply Systems
}

\author{
N.A.VYSOTSKAYA, B.N. KABYLBEKOVA, K.A. BEKZHIGITOVA, \\ R. SPABEKOVA and K.T. KURBANBEKOV \\ Department of Chemistry, M.Auezov South Kazakhstan State University, Kazakhstan, \\ Shymkent city, Tauke-khan ave. 5, Kazakhstan. \\ *Corresponding author E-mail: balzhan.kbn@bk.ru \\ http://dx.doi.org/10.13005/ojc/330643
}

(Received: April 06, 2017; Accepted: June 01, 2017)

\begin{abstract}
The composition of corrosion-scale deposits, consisting of alkali metal carbonates, silicates and sulfates, formed on the metal surface in the form of dense and loose deposits, depending on the composition of the heat carrier (water) formed on the inner surface of pipelines in heat supply systems using a scanning electron microscope brand JSM-6490LV with systems of energy dispersive microanalysis INSA Energu and structural analysis HKL-Basic with a useful increase of 300,000 in combination with a high-performance liquid chromatograph Varian Pro Star was investigated. The solutions of acids: hydrochloric, oxalic, citric and sulphamic acids, often used as washing reagents in heat supply systems, are shown, the rate of corrosion and loss from corrosion under wash conditions were investigated. The process of selecting the optimal module of sodium silicate used as an inhibitor in the washing solution was determined, it is studied and experimentally installed dependence of the corrosion rate index on the inhibitor module and the time of aging of the sample in the inhibitor solution was studied and experimentally established in order to create an effective protective film with a high aftereffect. An instrument-technological scheme for chemical washing of the internal surface of pipelines is given to remove scaling deposits.
\end{abstract}

Keywords: Corrosion-scum deposits, Inhibitor, Chemical purification.

\section{INTRODUCTION}

The chemical composition of corrosionscale deposits ${ }^{1-3}$ is classified as: alkaline-earth, complex in composition silicate, iron, manganese and copper. The compositions of alkaline earth and complex silicate are $90 \%$ composed of carbonates, sulfates, silicates, and alkali metal phosphates and are formed as solid, dense crystalline deposits in the pipes of thermal networks, and in the boiling point of alkaline waters fall out in the form of slurries.

Impurities of phosphates, iron and manganese in elevated concentrations in water contribute to the formation of loose crumbling scale, in the case of the copper content in water, copper scum is formed in the form of layered deposits. When boilers are operated with a change in the 
hydrodynamic and thermal conditions, highly dispersed sludge from the walls of the boiler pipes is washed out, containing complex carbonates and phosphates. Such a slurry is captured by a heat carrier and also participates in scale formation processes, contributing to the formation of denser layers of deposits on the inner surface of the pipe. Elimination of scaling deposits from the internal surface of pipelines in heat supply systems is carried out by various methods, one of which is the selection of an effective washing solution composition ${ }^{4,5}$.

When contaminated heat exchangers in heat supply systems with hardly soluble carbonates and iron oxides, acids such as hydrochloric, sulphuric, sulphamic and other acids are often used as detergents. Advantages of some acids are their cheapness and non-toxicity with respect to the metal surface ${ }^{6}$.

\section{MATERIALS AND METHODS}

When solutions (especially hydrochloric acid solutions) are used for chemical removal of corrosion-scale deposits from the steel surface of pipelines in heat supply systems, partial dissolution of pipelines ${ }^{7}$ occurs. Using the useful properties of acids, care must be taken to ensure that acids are not as corrosive to metal equipment as possible. An effective means for eliminating this undesirable phenomenon is the use of various corrosion inhibitors ${ }^{8-10}$, which mechanism of action consists in the reduction of hydrogen ions formed due to the dissociation of carbon dioxide, which appears in water upon dissolution of free carbon dioxide and contributes to the fact that the initial ionization rate of iron Becomes proportional to the concentration of hydrogen ions. Recently, sodium silicates have been widely used as an inhibitor, the effective action of which largely depends on its modulus. Sodium silicate with the ratio $\left[\mathrm{Na}_{2} \mathrm{O}\right] /\left[\mathrm{SiO}_{2}\right]$ : sodium metasilicate $\mathrm{Na}_{2} \mathrm{SiO}_{3}$ or $\mathrm{Na}_{2} \mathrm{O} \times \mathrm{SiO}$ (the module is equal to 1), $\mathrm{Na}_{2} \mathrm{Si}_{2} \mathrm{O}_{5}$ or $\mathrm{Na}_{2} \mathrm{O} \times 2 \mathrm{SiO}_{2}$ (module 2), or $\mathrm{Na}_{2} \mathrm{O} \times 3 \mathrm{SiO}_{2}$ (module 3) are used as passivators creating a protective film on the metal surface.

The effective heat supply of public, industrial and domestic facilities with heat through the heat supply system depends on the cleanliness of the internal surface of the heat exchange structures (radiators, heat exchangers, heating surfaces of boilers, various units). Due to the emerging corrosion process, products of cathodic and anodic reactions $\left(\mathrm{OH}^{-}\right.$and $\left.\mathrm{Fe}^{2+}\right)$ are formed on the internal surface of metal pipelines in heat exchangers, radiators on a metal surface, capable of influencing the carbon dioxide equilibrium and contributing to the deposition of a significant amount of carbonate sediments that can cause considerable difficulty in returning of heat from the coolant.

The development of the instrumenttechnological scheme for cleaning heat supply systems from corrosion-scale deposits solves the problem of free passage of the coolant through the system and at the same time reduces the fuel consumption for heating the coolant.

\section{RESULTS AND DISCUSSION}

The experiment consisted in the study of the composition of the corrosion-scale deposits formed on the inner surface of pipelines operating in the heat supply systems of the city of Shymkent, Republic of Kazakhstan. Knowledge of the composition of corrosion-scum deposits in the pipes of heat supply systems contributes to the correct selection of wash solutions to remove accumulated deposits.

A scanning electron microscope made it possible to determine the composition of the scale deposits shown in Figure.1.

The capabilities of the electron microscope allow for a qualitative and quantitative analysis of scale deposits. Corrosion-scale deposits stimulate the general and local corrosion of iron (pipes) as a result of which the pipe, boiler, heat exchanger, radiator is destroyed, and there is an overexpenditure of electricity during operation by approximately $8-10 \%$ with a system thickness of up to $2 \mathrm{~mm}$.

A 300,000 useful magnification of the microscope in combination with the highly efficient liquid chromatograph Varian Pro Star makes it possible to identify various impurities and inclusions in the test sample. 


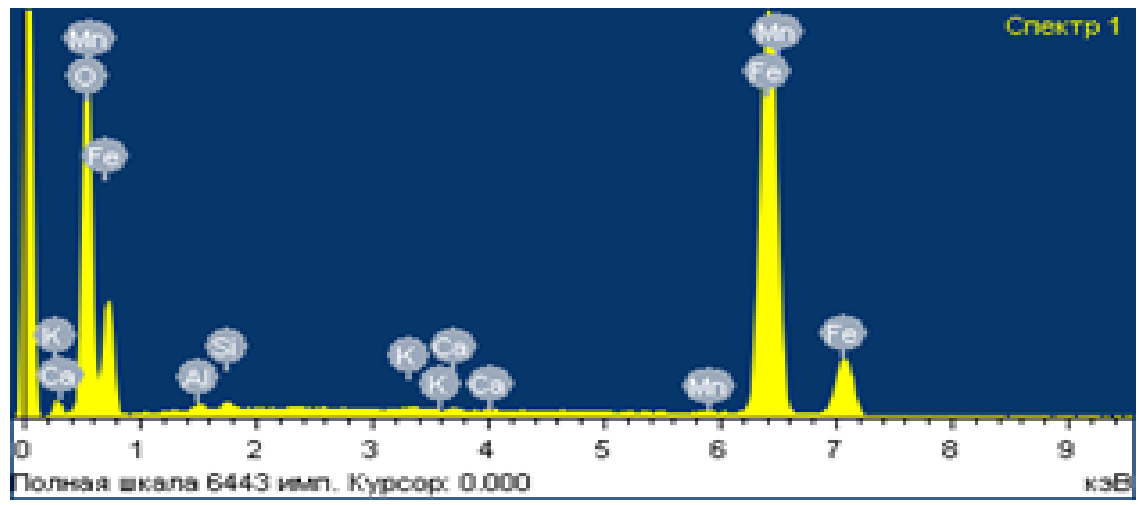

\begin{tabular}{lc} 
Element & Weight,\% \\
\hline $\mathrm{O}$ & 24.00 \\
$\mathrm{Al}$ & 0.56 \\
$\mathrm{Si}$ & 0.94 \\
$\mathrm{~K}$ & 0.15 \\
$\mathrm{Ca}$ & 0.13 \\
$\mathrm{Mn}$ & 0.43 \\
$\mathrm{Fe}$ & 73.78 \\
\hline
\end{tabular}
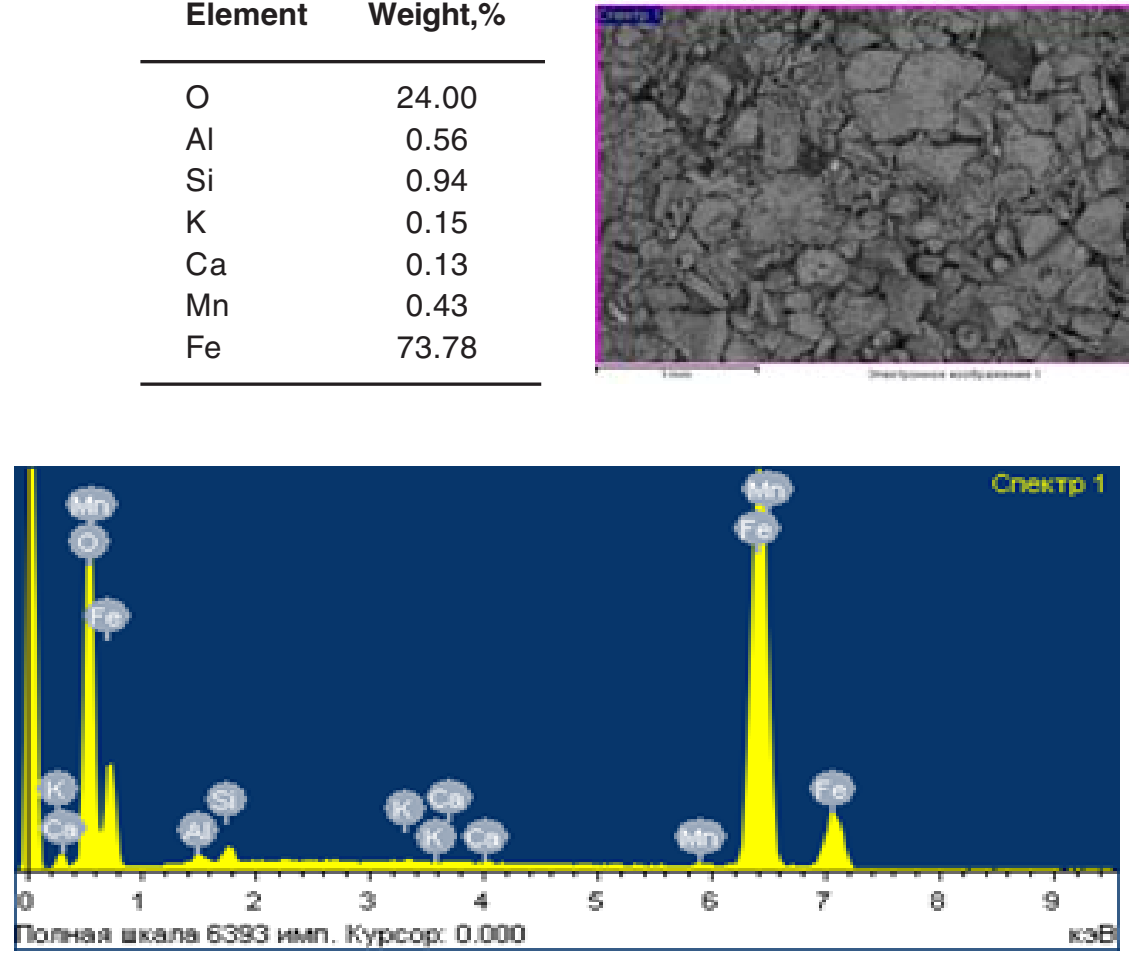

\begin{tabular}{cc} 
Element & Weight,\% \\
\hline $\mathrm{O}$ & 24.07 \\
$\mathrm{Al}$ & 0.43 \\
$\mathrm{Si}$ & 0.41 \\
$\mathrm{~K}$ & 0.17 \\
$\mathrm{Ca}$ & 0.18 \\
$\mathrm{Mn}$ & 0.43 \\
$\mathrm{Fe}$ & 74.31 \\
\hline
\end{tabular}

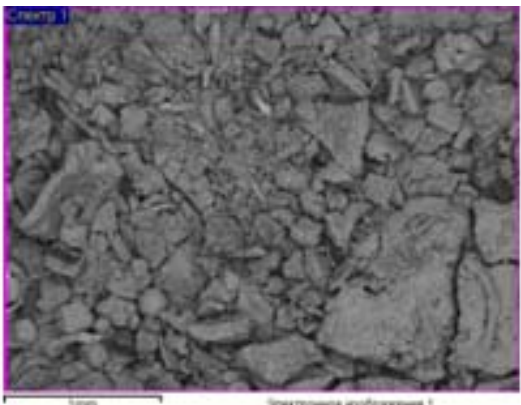

Fig. 1. Quantitative composition and structure of component-elements in the corrosion-scale deposits removed from the surface of a metal pipe 
Possibilities of the microscope allow to determine the content of all elements in the analyzed samples in percent by weight, and also to see the structure of the analyzed samples.

As can be seen from Fig. 1, the elements in the composition of corrosion-scale deposits taken from the inner surface of metal pipelines in the heat supply systems of Shymkent have a composition close to alkaline-earth. Analysis of the composition of the elements in scale deposits shows that the main component in both pipes is iron.

It is interesting to study the dissolution of corrosion-scale deposits on the inner surface of pipelines in solutions of various acids: sulphamic, hydrochloric, oxalic and citric.

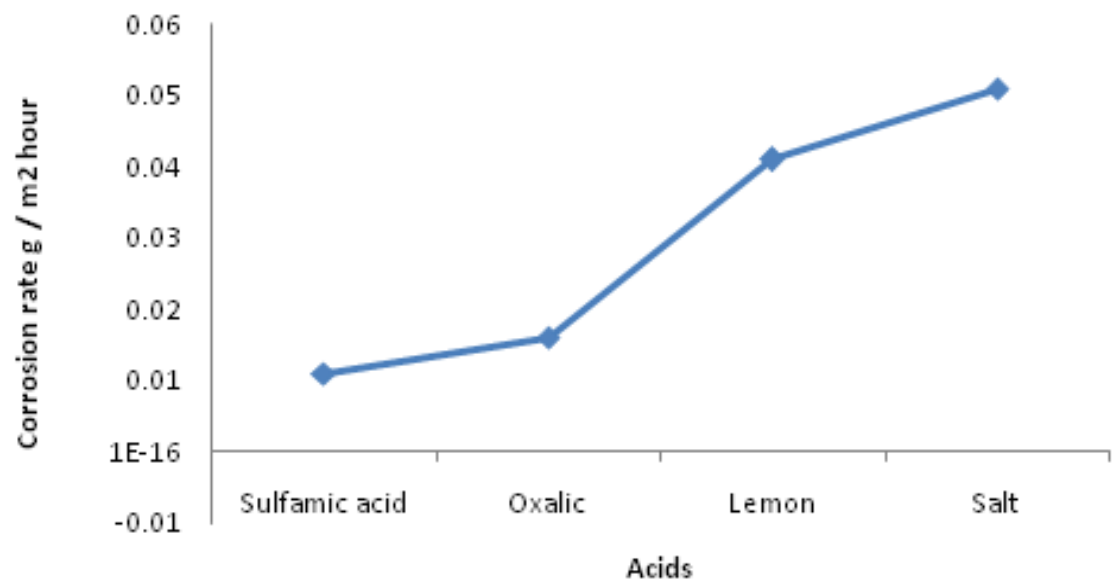

Fig. 2. Dependence of the corrosion rate on samples activated by various acid solutions and treated with an inhibitor

Table. 1: Solubility indices of elements removed from steel pipes in acid solutions

\begin{tabular}{|c|c|c|}
\hline Acids & $\begin{array}{l}\text { Elements in the scale deposits } \\
\text { prior to their dissolution in acid }\end{array}$ & $\begin{array}{l}\text { Elements in the scale deposits } \\
\text { after their dissolution in acid }\end{array}$ \\
\hline Sulphamic acid & $\mathrm{Al}, \mathrm{Si}, \mathrm{K}, \mathrm{Ca}, \mathrm{Mn}, \mathrm{Fe}$ & traces of iron \\
\hline Hydrochloric acid & $\mathrm{Al}, \mathrm{Si}, \mathrm{K}, \mathrm{Ca}, \mathrm{Mn}, \mathrm{Fe}$ & traces of iron and manganese \\
\hline Oxalic acid & $\mathrm{Al}, \mathrm{Si}, \mathrm{K}, \mathrm{Ca}, \mathrm{Mn}, \mathrm{Fe}$ & traces of silicon, iron, manganese \\
\hline Citric acid & $\mathrm{Al}, \mathrm{Si}, \mathrm{K}, \mathrm{Ca}, \mathrm{Mn}, \mathrm{Fe}$ & traces of iron, aluminum, silicon \\
\hline
\end{tabular}

Table. 2: Corrosion Rate Parameters on Steel Tubes Activated by Various Acid Solutions

\begin{tabular}{llll}
\hline $\begin{array}{l}\text { Acid solutions } \\
\text { for surface } \\
\text { activation }\end{array}$ & $\begin{array}{l}\text { Iron weight left } \\
\text { from the surface } \\
\text { of the steel } \\
\text { tube, } \mathrm{g}\end{array}$ & $\begin{array}{l}\text { Corrosion } \\
\text { rate, } \mathrm{g} / \mathrm{m}^{2} \\
\text { hour }\end{array}$ & $\begin{array}{l}\text { Loss from } \\
\text { corrosion from } \\
\text { the sample, } \\
\mathrm{mm} / \text { year }\end{array}$ \\
\hline $\begin{array}{l}\text { Sulphamic acid } \\
\text { Lemon }\end{array}$ & 0,0046 & 0,0110 & 0,0050 \\
$\begin{array}{l}\text { Oxalic } \\
\text { Salt }\end{array}$ & 0,0199 & 0,0410 & 0,0187 \\
& 0,0078 & 0,0162 & 0,0070 \\
& 0,0240 & 0,0510 & 0,0230 \\
\hline
\end{tabular}


The suspended scale deposits removed from the inner surface of the steel tubes, with the element composition recorded with an electron microscope, were placed in a solution of various acids with a concentration of $5 \%$ by mass: first, sulfamine, in the second hydrochloric acid, in the third oxalic acid, in the fourth citric acid and left for $5 \mathrm{~h}$ (the minimum time for cleaning pipelines from scaling deposits in practice) at room temperature. After a predetermined time, the acid composition was analyzed for the content of said components. Table. 1 shows the data on the solubility of elements in the scale scale in solutions of various acids.

To obtain the results of dissolving scaling deposits, steel tubes with an area of $0.02 \mathrm{~m}^{2}$ were selected, weighed on analytical scales and activated with various acids for $4 \mathrm{~h}$, then water was circulated through the tubes at a circulation speed of $0,5 \mathrm{~m} / \mathrm{sec}$. The corrosion rate was calculated from the mass of iron transferred from the steel surface of the tube to the solution.
Table. 2 shows the data on the corrosion rate of the steel sample as a function of the acid composition.

According to the data in Table. 2, a graphical dependence of the corrosion rate on the samples activated by various acids is constructed. The rate of corrosion on acid-activated surfaces of steel tubes is clearly visible from the Fig. The lowest corrosion rate is observed in a solution of sulphamic acid, the largest in solution of hydrochloric acid.

Comparing the indicators of Tables. 1 and 2 , we can draw conclusions. Virtually all impurities in scale deposits are readily soluble in a solution of sulphamic acid at the lowest corrosion rate (Figure. 2).

Proceeding from the foregoing, the task of selecting the chemical composition of the washing solution to remove corrosion-scum deposits from the internal surface of pipelines in heat supply systems can be successfully solved using a solution of sulphamic acid.

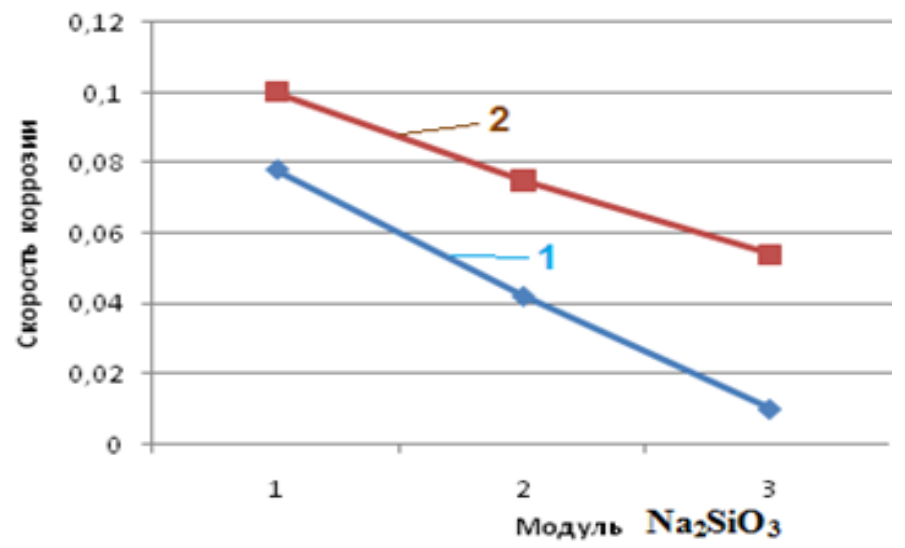

Fig. 3. Dependence of the corrosion rate on the inhibitor module on activated (curve 1) and inactivated (curve 2) acid steel samples

Table. 3: The corrosion rate of steel pipes as a function of the inhibitor module

\begin{tabular}{|c|c|c|}
\hline \multirow{2}{*}{$\begin{array}{l}\text { Inhibitor, indicator } \\
\text { of the module }(\mathrm{m})\end{array}$} & \multicolumn{2}{|c|}{ Corrosion rate, $\mathrm{g} / \mathrm{m}^{2 *} \mathrm{~h}$} \\
\hline & $\begin{array}{l}\text { activated sample } \\
\text { surface }\end{array}$ & $\begin{array}{l}\text { non-activated sample } \\
\text { surface }\end{array}$ \\
\hline $\mathrm{Na}_{2} \mathrm{SiO}_{3}, \mathrm{~m}=1$ & 0,079 & 0,100 \\
\hline $\mathrm{Na}_{2} \mathrm{SiO}_{3}, \mathrm{~m}=2$ & 0,042 & 0,079 \\
\hline $\mathrm{Na}_{2} \mathrm{SiO}_{3}, \mathrm{~m}=3$ & 0,015 & 0,057 \\
\hline
\end{tabular}




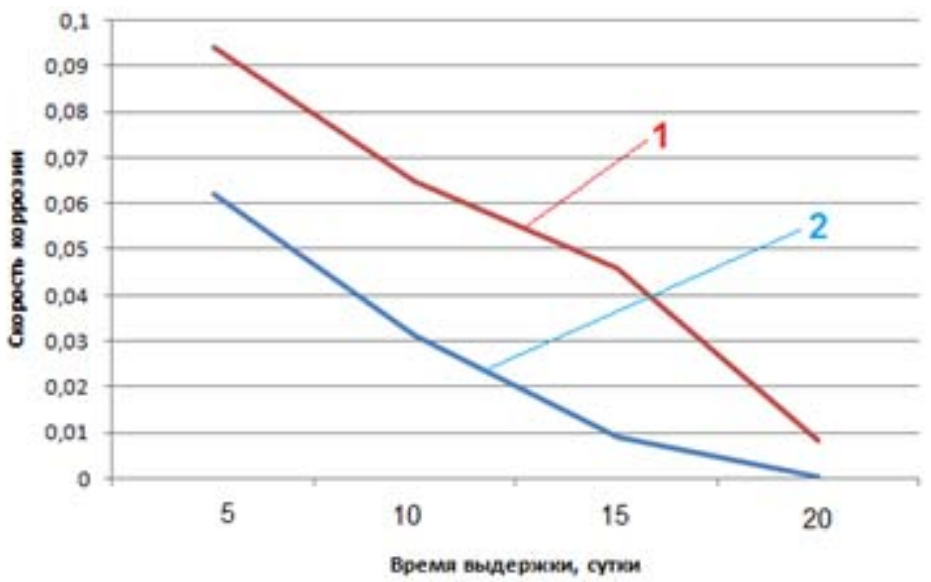

Fig. 4. Dependence of the corrosion rate of a steel sample on the aging time in an inhibitor-sodium silicate solution (curve 1 is inactive, curve 2 is the activated surface)

Table. 4: The corrosion rate of steel samples treated at different times in a solution of the inhibitor sodium silicate

\begin{tabular}{lll}
$\begin{array}{l}\text { Time of sample holding } \\
\text { in solution of inhibitor, } \\
\text { sodium silicate }\end{array}$ & $\begin{array}{l}\text { Corrosion rate, } \mathrm{g} / \mathrm{m}^{2 *} \mathrm{~h} \\
\text { non-activated sample } \\
\text { surface }\end{array}$ & surface \\
\hline 5 hours & 0,062 & 0,094 \\
10 hours & 0,031 & 0,065 \\
15 hours & 0,009 & 0,046 \\
20 hours & 0,00017 & 0,0084
\end{tabular}

Table. 3 and Fig. 3 show the corrosion rate indicators for non-activated and sulphamic acid-activated steel tubes treated in solutions of an inhibitor with a different modulus.

Reducing the corrosion rate on acid-activated samples treated with an inhibitor with modulus $\mathrm{m}=3$ is more pronounced than on unactivated samples with the same inhibitor module.

Table. 4 shows the data of the study of the influence of the aging time of the samples in the inhibitor solution with modulus $m=3$ on the corrosion rate of steel samples activated in a solution of sulphamic acid.

The graphical dependence of the corrosion rate of a steel sample activated by sulphamic acid and a non-activated sample on the time of aging in the inhibitor solution is shown in Figure. 4.

Important in the operation of heat exchange equipment is the creation of "survivability" of protective passivating films formed on the inner surface of the stiff pipelines (Figure. 4).

\section{CONCLUSIONS}

Using the method of energy dispersion analysis, the composition of corrosion-scale deposits on the metal surface of pipelines in heat supply systems is established. The possibility of dissolution of corrosion-scale deposits in solutions of various acids is shown. Calculated the corrosion rate on the metal surface of the pipelines. The effect of the inhibitor module on the lifetime of a passivating film. The composition of the acid is indicated for use in washing solutions. 


\section{REFERENCES}

1. Ilyin, D.; Zhilin, V. Heat supply news. 2010, 2 C.37.

2. Balaban-Irmenin, Yu.V.; Fokina, N.G.; Petrova, S.Yu. Proceedings of the scientificpractical conference "Modern methods of preparation and protection of equipment against corrosion and scale formation". Moscow: IEC EXPO CENTER, 2009, 12-20.

3. Glazyrin, A.I.; Glazyrin, S.A.; Glazyrin, A.A. Collected materials of the 1 International Scientific and Practical Conference "Scientific Provision of Housing and Communal Services". Astana, 2012, 57-60.

4. Balaban-Irmenin, Yu.V.; Fedoseev, V.S.; Bessolitsyn, S.E.; Rubashov, A.M. Thermal energy. 1994, 8, 30-37.

5. Akolzin, P.A. Prevention of corrosion of technical water and heat supply equipment. -Moscow: Metallurgy, 1988, 94

6. Gabitov, A.I. Results and perspectives in the theory and practice of corrosion control. -Moscow: Reactive, 1998, 121.

7. Balaban-Irmenin, Yu.V.; Litovskikh, V.M.; Rubashov, A.M. Heat supply news, 2008, 49-52.

8. Akolzin, A.P.; Zhukov, A.P. Oxygen corrosion of chemical production equipment. -Moscow: Chemistry, 1985, 239.

9. Glazyrin, A.l.; Glazyrin, A.A.; Orumbayev, R.K. Corrosion and conservation of heat and power equipment. -Pavlodar: ECO, 2011, 728.

10. Glazyrin, A.I.; Kostrikina, E.Yu. Conservation of power equipment. -Moscow: Energoatom izdat, 1987, 168. 